\title{
Development Strategy of fruit and vegetable intake based on comprehensive evaluation model
}

\author{
XunWang ${ }^{\mathrm{a}}$,ZhifengWu ${ }^{\mathrm{b}}$, Xunjian $\mathrm{Yu}^{\mathrm{c}}$ \\ College of Telecommunications \& Information Engineering, \\ Nanjing University of Posts and Telecommunications \\ Nanjing 210003, P.R. China \\ aanwg1990@163.com,bnjuptwzf@163.com,cyu_xunjian@163.com
}

\begin{abstract}
Cluster analysis and principal component analysis method to analyze the nutritional content of fruits and vegetables that: Vitamin A, C, E, sodium, potassium, calcium, ferrum, zinc, and phosphorusis the main nutrients.In addition, we firstly calculate per capita consumption of the intake of different age groups for each of the major nutrients, and make the product of their corresponding weights, then, we givethe final comprehensive health evaluation model. Using this model, we can predict health score value of all ages in 2020, and compare the score to the nutritional status of the score sheet.

Keywords:Cluster analysis; principal component analysis;comprehensive health evaluation model
\end{abstract}

\section{Introduction}

Fruits and vegetables are important agricultural products, mainly for the human body to provide minerals, vitamins, dietary fiber. In recent years, Chinese fruit and vegetable acreage and yield are becoming richer, but most residents ignore the human body needs a healthy balanced diet, making the fruit and vegetable consumption (the variety and quantity) in meeting the residents balanced nutrition requirements, almost disorder, thereby affecting fruit and vegetable production.

The data resource is based on probem D in the 11th National Postgraduate Mathematic Contest in Modeling.To find out the status of Chinese nutrient intake, we combine the scope and the results have been predictable of per capita consumption of various nutrients, to evaluate the reasonable in the current intake of nutrition. And then, we forecast this result till 2020, to analysis human nutrition and health status of Chinese residents. 


\section{Analysis}

We have established a comprehensive health evaluation model, which is mainly calculating the product of human intake of major nutrients with its weight factor. Then, the model will automatically score the results and final determinate the human nutrition intake level is qualified or not.

\section{System model}

\subsection{Select the important nutrients}

$\mathrm{R}$ cluster analysis method is used in fruits and vegetable. Then, in each selected category, using principal component analysis, calculated the contribution to the overall index. Choose a large contribution of nutrients species as an important component.

\subsection{Crowd classification}

The special populations, such as infants, pregnant women, are excluded.According to the nutritional intake of the population, we roughly divided into four groups: 1 to 17 years old (children / adolescents), 18 to 44 years old (young adults), 45 to 69 years old (middle-aged) and 70 to above (the elderly).

\subsection{Intake of important nutritional factors}

Per capita intake of important nutritional can be determined by the per capita consumption of the main nutrients and the proportion of total consumption.

\section{4 weight coefficient of nutrients for the crowd}

Demand for different populations of the same nutrients are not identical, and the weight coefficients satisfy that the calculateddifferent groups score can directly compare to the score sheet .

In the objective function value of each age group, the argument is: the actual consumption / reference amount. In every age group, we calculate the correspondingweight coefficients of p major nutrients.

Take young adults as example:

$$
Y_{\text {score }}=x_{1} m_{1}+x_{2} m_{2}+\cdots+x_{p} m_{p}
$$

where $x_{i}(i=1,2, \cdots, p)$ is the argument.If actual consumption is larger than reference amount, then $x_{i}=1$; otherwise, $x_{i}$ is the actual consumption / reference amount. $m_{i}(i=1,2, \cdots, p)$ is the correspondingweight coefficients of $p$ major nutrients. Then, the Score Matrix is: 


$$
\left[Y_{\text {score } 1}, Y_{\text {score } 2}, \cdots, Y_{\text {score } 4}\right]^{T}=\left[\begin{array}{cccl}
m_{11} & m_{12} & \cdots & m_{1 p} \\
m_{21} & m_{22} & \cdots & m_{2 p} \\
\vdots & \vdots & \vdots & \vdots \\
m_{p 1} & m_{p 2} & \cdots & m_{p p}
\end{array}\right]\left[x_{1}, x_{2}, \cdots, x_{p}\right]^{T}
$$

The detailed calculation of weight coefficients is in the next section.

\section{Model solution}

We take the various nutrients as each index value to analyze.Firstly, $\mathrm{R}$ cluster analysis is used to solve the correlation coefficient between m nutrients, obtained correlation coefficient matrix, and divide into some packet.

We define $x_{j}=\left(x_{1 j}, x_{2 j}, \cdots, x_{n j}\right)^{T} \in R^{n}(j=1,2, \cdots, m)$ as the correlation coefficient, then the measure of correlation is

$$
r_{j k}=\frac{\sum_{i=1}^{n}\left(x_{i j}-\overline{x_{j}}\right)\left(x_{i k}-\overline{x_{k}}\right)}{\left[\sum_{i=1}^{n}\left(x_{i j}-\overline{x_{j}}\right)^{2} \sum_{i=1}^{n}\left(x_{i k}-\overline{x_{k}}\right)^{2}\right]^{\frac{1}{2}}}
$$

Based on(3), we obtain the correlation coefficient matrix. The maximum coefficient is used to get the classification results.

We divide the nutrients into four groups. In each group, using principal component analysis, we get 9 major nutrition: Vitamin A, vitamin C, vitamin E, sodium, calcium, iron, zinc, potassium and phosphorus.

Next, we define

$$
S_{\text {sum }}=17 A+27 B+25 C+31 D
$$

where $\eta_{1}=A / S_{\text {aver }}, \quad \eta_{2}=B / S_{\text {aver }}, \quad \eta_{3}=C / S_{\text {aver }}, \quad \eta_{4}=D / S_{\text {aver }}$. $S_{\text {aver }}=S_{\text {sum }} / 100=2140$. the energy weighting factor $\eta_{1} \sim \eta_{4}$ represents the proportion of each age group in 9 major nutrition, we obtain $\eta_{1}=0.83945$, $\eta_{2}=1.32398, \eta_{3}=1.046, \eta_{4}=0.79439$, Then calculate the annual intake of 9 nutrient content for each age group.

The nutrient amount of each age group is $\left[a_{1,1}, a_{1,2}, \cdots a_{1, \mathrm{n}} \cdots, a_{\mathrm{m}, \mathrm{n}}\right]$, firstly, we calculate the corresponding weight $\left[\theta_{1,1}, \theta_{1,2}, \cdots \theta_{1, \mathrm{n}} \cdots, \theta_{\mathrm{m}, \mathrm{n}}\right]$, which is given by

$$
\theta_{i, j}=\frac{a_{i, j}}{a_{1, j}+a_{2, j}+\cdots+a_{m, j}}, j=1,2, \cdots n
$$


where $\sum_{i=1}^{m} \theta_{i, j}=1, j=1,2, \cdots n$.

The corresponding weight of nutrient score $\left[\mu_{1,1}, \mu_{1,2}, \cdots \mu_{1, \mathrm{n}} \cdots, \mu_{\mathrm{m}, \mathrm{n}}\right]$, is given by

$$
\mu_{i, j}=\frac{\theta_{i, j}}{\theta_{i, 1}+\theta_{i, 2}+\cdots+\theta_{i, \mathrm{n}}}, i=1,2, \cdots m
$$

where $\sum_{j=1}^{n} \mu_{i, \mathrm{j}}=1, \mathrm{i}=1,2, \cdots m$. The detailed result is shown in Table 1 .

Table 1 Nutrient's weight in each age group

\begin{tabular}{|c|c|c|c|c|c|c|c|c|c|}
\hline & $\begin{array}{l}\text { potass } \\
\text { ium } \\
/ \mathrm{mg}\end{array}$ & $\begin{array}{l}\text { sodi } \\
\text { um } \\
/ \mathrm{mg}\end{array}$ & $\begin{array}{l}\text { calci } \\
\text { um } \\
/ \mathrm{mg}\end{array}$ & $\begin{array}{c}\text { phosph } \\
\text { orus } \\
\text { /mg }\end{array}$ & $\begin{array}{c}\text { ferru } \\
\mathrm{m} \\
/ \mathrm{mg}\end{array}$ & $\begin{array}{l}\text { Zinc } \\
/ \mathrm{mg}\end{array}$ & $\begin{array}{l}\text { VA } \\
\text { /ug }\end{array}$ & $\begin{array}{l}\mathrm{VC} / \\
\mathrm{mg}\end{array}$ & $\begin{array}{l}\mathrm{VE} \\
/ \mathrm{mg}\end{array}$ \\
\hline $\begin{array}{c}\text { childre } \\
\text { n/ } \\
\text { adolesc } \\
\text { e-nts } \\
\end{array}$ & $\begin{array}{c}10.39 \\
\%\end{array}$ & $\begin{array}{c}7.43 \\
\%\end{array}$ & $\begin{array}{c}12.1 \\
9 \%\end{array}$ & $\begin{array}{c}13.41 \\
\%\end{array}$ & $\begin{array}{c}12.9 \\
3 \%\end{array}$ & $\begin{array}{c}12.2 \\
1 \%\end{array}$ & $\begin{array}{c}12.4 \\
9 \%\end{array}$ & $\begin{array}{l}10.8 \\
6 \%\end{array}$ & $\begin{array}{c}8.09 \\
\%\end{array}$ \\
\hline $\begin{array}{l}\text { young } \\
\text { adults }\end{array}$ & $\begin{array}{c}11.86 \\
\%\end{array}$ & $\begin{array}{c}11.9 \\
3 \%\end{array}$ & $\begin{array}{l}10.5 \\
8 \%\end{array}$ & $\begin{array}{c}10.41 \\
\%\end{array}$ & $\begin{array}{l}10.5 \\
3 \%\end{array}$ & $\begin{array}{c}11.4 \\
1 \%\end{array}$ & $\begin{array}{c}9.65 \\
\%\end{array}$ & $\begin{array}{l}11.8 \\
6 \%\end{array}$ & $\begin{array}{l}11.7 \\
6 \%\end{array}$ \\
\hline $\begin{array}{c}\text { middle- } \\
\text { aged }\end{array}$ & $\begin{array}{c}11.09 \\
\%\end{array}$ & $\begin{array}{c}12.2 \\
0 \%\end{array}$ & $\begin{array}{l}10.3 \\
6 \%\end{array}$ & $\begin{array}{c}10.65 \\
\%\end{array}$ & $\begin{array}{l}10.7 \\
7 \%\end{array}$ & $\begin{array}{l}10.6 \\
0 \%\end{array}$ & $\begin{array}{l}11.3 \\
9 \%\end{array}$ & $\begin{array}{c}10.9 \\
0 \%\end{array}$ & $\begin{array}{c}12.0 \\
3 \%\end{array}$ \\
\hline $\begin{array}{l}\text { the } \\
\text { elderly }\end{array}$ & $\begin{array}{c}10.94 \\
\%\end{array}$ & $\begin{array}{c}12.0 \\
4 \%\end{array}$ & $\begin{array}{l}11.5 \\
5 \%\end{array}$ & $\begin{array}{c}10.50 \\
\%\end{array}$ & $\begin{array}{c}10.6 \\
3 \%\end{array}$ & $\begin{array}{c}10.4 \\
6 \%\end{array}$ & $\begin{array}{c}11.2 \\
4 \%\end{array}$ & $\begin{array}{l}10.7 \\
6 \%\end{array}$ & $\begin{array}{c}11.8 \\
7 \%\end{array}$ \\
\hline
\end{tabular}

(The data resource is based on probem D in the 11th National Postgraduate Mathematic Contest in Modeling)

We establish a nutrition score sheet to quantify our results, the score sheet is shown in Table 2.

Table 2 nutrition score sheet

\begin{tabular}{c|c}
\hline score & evaluation \\
\hline above 80 & $\mathrm{~A}$ \\
\hline $70-79$ & $\mathrm{~B}$ \\
\hline $60-69$ & $\mathrm{C}$ \\
\hline below 60 & $\mathrm{D}$ \\
\hline
\end{tabular}

The score from 2002 to 2010 can be calculated by (1), as depicted in Fig2. 


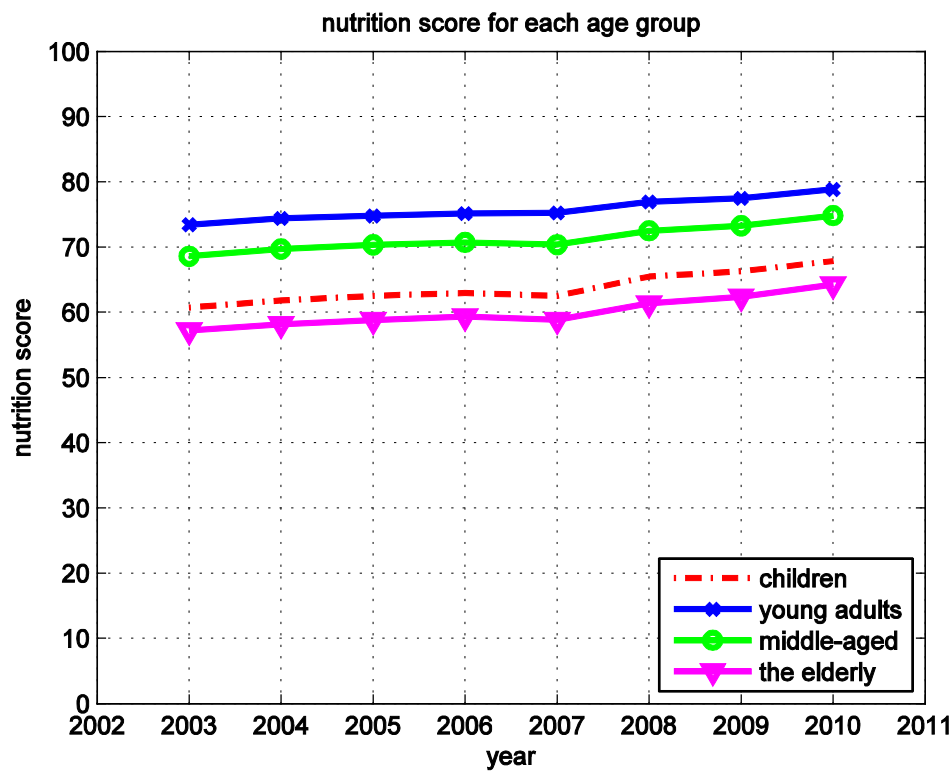

‘Fig1. Each age group nutrition’s score schematic

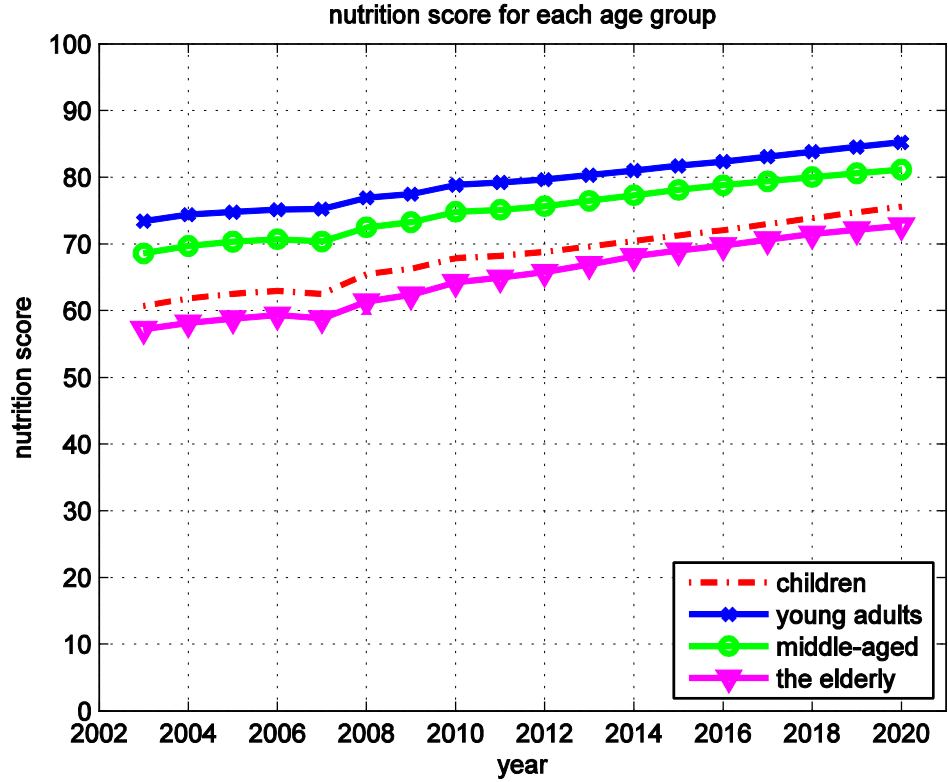

Fig2. Each age group nutrition's score prediction

Fig1 reveals that the current minerals, vitamins and other nutrition's annual intake remain to increase.In particular, children and the elderly, should arrange food more reasonable, with balanced nutrients, in order to promote the intake of each major nutrition and improvethe current nutritional status. The young and 
middle-aged, in the present circumstances, improve the living law and enhance intake of nutrients appropriately, could reach a better level in the coming years.

As can be seen from Fig 2, by 2020, the nutritional score are showing a rising trend. In 2018, young adults andmiddle-aged can achieved B, children and the elderly can reach C. Overall, according to the current intake of minerals, vitamins, dietary fiber and other nutrients, coupled with a reasonable diet adequate, balanced nutrition absorption, improving nutritional status, to 2020, human nutrition and health status constantly getting better.

\section{Conclusions}

Cluster analysis and principal component analysis method to analyze the nutritional content.In addition, we proposedthe comprehensive health evaluation model. Using this model, we predicted health score value of all ages in 2020, and compared the score to the nutritional status of the score sheet.

\section{References}

[1] Jiang Qiyuan, XieJinxing, a mathematical model (fourth edition),. Higher Education Press, 2011.1.1

[2] Wang Donghua, multivariate statistical analysis with spss application, East China University of Science and Technology Press, 2010.9.1

[3] Gao Huixuan, Application of Multivariate Statistical Analysis, Peking University Press, 2005.1.1

[4] WangZhenglin, Gong Chun, He Qian, proficient in matlab scientific computing, Electronic Industry Press, 2012.10.1

[5] Yuan Xinsheng, ShaoDahong, Yu Shilian, Lingo and Excel in Mathematical Modeling Applications, Science Press, 2007.1 